\title{
Rocuronium versus Vecuronium for laparoscopic cholecystectomy
}

Tabdar $\mathbf{S}^{1}$, Kadariya $\mathbf{E R}^{2}$

'Sushila Tabdar, Assistant Professor, Department of Anaesthesiology and Intensive Care, Kathmandu Medical College Teaching Hospital, Kathmandu, Nepal. ${ }^{2}$ Ekraj Kadariya, Lecturer, Trichandra Multiple Campus, Tribhuvan University, Kathmandu, Nepal.

\section{ABSTRACT}

Background: Laparoscopic cholecystectomy under general anaesthesia using Vecuronium is quite common these days. Some alarming complications like severe bradycardia and asystole after creation of carboperitoneum is not uncommon after its injection which is very stressful to both surgeons and anaesthesiologists. As an alternative, Rocuronium has been found safe in this regard till now used in many general anaesthesia requiring cases. So, it can be useful in laparoscopic cholecystectomy as well.

Objective: To compare the haemodynamic, respiratory parameters and complications between Vecuronium and Rocuronium.

Methods: In this randomised prospective double blind study conducted at Kathmandu Medical College from March 2013 to September 2013, a total of sixty patients of American Society of Anaesthesiologist (ASA) physical status I and II planned for laparoscopic cholecystectomy were randomly divided into two groups of thirty each by envelope method, with one group receiving Rocuronium and the other group receiving Vecuronium as muscle relaxants. Group A received injection Pethidine $1 \mathrm{mg} / \mathrm{kg}$, Propofol $2.5 \mathrm{mg} / \mathrm{kg}$ and Vecuronium $0.1 \mathrm{mg} / \mathrm{kg}$ for induction. Group B received injection Pethidine $1 \mathrm{mg} / \mathrm{kg}$, Propofol $2.5 \mathrm{mg} / \mathrm{kg}$ and Rocuronium $0.6 \mathrm{mg} / \mathrm{kg}$ for induction. After intubation the whole anaesthesia was maintained with oxygen, air, halothane and intermittent positive pressure ventilation. Intraoperative monitoring used were Pulse rate (PR), mean arterial pressure (MAP), arterial Oxygen saturation $\left(\mathrm{SpO}_{2}\right)$, end tidal Carbondioxide $\left(\mathrm{ETCO}_{2}\right)$, electro cardiography (ECG) and peripheral nerve stimulator (PNS). PR, $\mathrm{MAP}, \mathrm{SpO}_{2}, \mathrm{ETCO}_{2}$, ECG were recorded before muscle relaxant, one minute after muscle relaxant, before intubation, one minute after intubation, before skin incision, one minute after skin incision, before carboperitonium, one minute after carboperitoneum, before extubation and one minute after extubation. Carboperitoneum if occurred any were also noted. Statistical analysis was done by using SPSS 19 verson. Student $t$ test, Fisher's exact test and Chi square test were used for the final analysis where $P$ value $<0.05$ was considered significant.

Result: Using Vecuronium as a muscle relaxant for laparoscopic cholecystectomy resulted in haemodynamic alteration intraoperatively by a significant reduction of $P R$ one minute after carboperitoneum $(62.80 \pm 11.25$ versus $87.23 \pm 14.35$ in Rocuronium group) where $p<0.05$. Bradycardia requiring Atropine was significant in vecuronium group with $\mathrm{p}<0.05$.

Conclusion: Rocuronium is less likely to cause bradycardia as compared to Vecuronium in laparoscopic cholecystectomy.

Keywords: Cholecystectomy Laparoscopic, Haemodynamic, Pulmonary Paramaters, Rocuronium, Vecuronium.

\section{Address for Correspondence}

Dr. Sushila Tabdar

Assistant Professor

Department of Anaesthesiology and Intensive Care Kathmandu Medical College Teaching Hospital,

Sinamangal, Kathmandu, Nepal.

E-mail:sutabdar@yahoo.co.in

\section{INTRODUCTION}

aparoscopic cholecystectomy is one of the common -operations performed worldwide these days and so is true in our country as well. It offers several advantages over the open technique like reduction of stress response of surgery and anaesthesia intraoperatively, decrease in postoperative pain, reduction in pulmonary 
complications, decreased chance of wound infection and fast recovery with good cosmetic appearance ${ }^{1,2}$. Some important disadvantages are due to physiological effects of intraoperative carbondioxide insufflations (carboperitoneum) which causes major impacts on cardiorespiratory system. On cardiovascular system carboperitoneum can cause hypercapnoea leading to activation of sympathetic nervous system and increase in pulse rate, blood pressure and occurrence of dysarrythmias. Increased intra-abdominal pressure can cause venous compression leading to decrease preload, similarly severe bradycardia and asystole can occur if intense vagal stimulation occurs during trochar and needle insertion and peritoneal stretch ${ }^{3}$. Physiological changes in pulmonary system includes decrease lung volume and capacity, increase peak airway pressure, cephalad movement of diaphragm and reduced excursion, increase incidence of ventilation, perfusion mismatch, pneumothorax and pneumomediastinum ${ }^{4,5}$. When general anaesthesia is chosen good muscle relaxation with minimum alteration of cardiorespiratory function is beneficial. Vecuronium or Rocuronium both are used quite frequently in laparoscopic cholecystectomy these days but Vecuronium has been shown to cause increased incidence of bradycardia and even cardiac arrest in some cases especially after creation of carboperitoneum under general anaesthesia maintained with oxygen and Halothane ${ }^{6}$. Rocuronium on the other hand has been shown to have stable haemodynamics in maximum general anaesthesia requiring operations maintained similarly.

In our present study we have compared cardiorespiratory effects and complications between Vecuronium and Rocuronium during laparoscopic cholecystectomy maintained under general anaesthesia with oxygen and halothane.

\section{METHODS}

This randomized prospective double blind study was conducted at Kathmandu Medical College Teaching Hospital from March 2013 till September 2013 after ethical clearance from the ethical committee of the institute and informed written consent from the participants of the study. Sixty adult patients of both gender aged 20 to 60 years, weighing 40 to $65 \mathrm{~kg}$ and belonging to American Society Of Anaesthesiologist (ASA) class I and II posted for laparoscopic cholecystectomy under general anaesthesia were included in the study. The exclusion criteria were patients not meeting above criteria, having difficult airways, having significant cardiorespiratory and hepato-renal disease. Pre-anaesthetic evaluation was done one day prior to surgery and all the patients received tablet Diazepam $5 \mathrm{mg}$, Ranitidine $150 \mathrm{mg}$ and Metoclopramide $10 \mathrm{mg}$ the night before the surgery. Sample size was calculated by a formula $\mathrm{Z}^{2} \times \mathrm{P} \times(1-\mathrm{P}) /$ $\mathrm{C}^{2}$ and included as total 60 patients dividing into two groups ( $\mathrm{A}$ or $\mathrm{B}$ ) by envelop method. Anaesthesiologist who was blind to both groups conducted the study. Once the patient arrived the operation theatre intravenous fluid was started and basic monitors to record PR, ECG, MAP, $\mathrm{SpO}_{2}, \mathrm{ETCO}_{2}$ were attached. Group A patients were induced with Pethidine $1 \mathrm{mg} / \mathrm{kg}$, Propofol $2.5 \mathrm{mg} / \mathrm{kg}$ and Vecuronium $0.1 \mathrm{mg} / \mathrm{kg}$, group B patients were induced with similar dose of Pethidine and Propofol followed by Rocuronium $0.6 \mathrm{mg} / \mathrm{kg}$ after which mask ventilation was done for three minutes and trachea intubated. Maintenance of anaesthesia was done with $50 \%$ oxygen in air, Halothane 0.8-1\% and intermittent positive pressure ventilation. Base line monitoring of $\mathrm{PR}, \mathrm{ECG}, \mathrm{MAP}, \mathrm{SpO}_{2}$, $\mathrm{ETCO}_{2}$ was done and same parametres were noted one minute after the muscle relaxant, before intubation, one minute after intubation, before carboperitoneum, one minute after carboperitoneum, before skin incision, one minute after skin incision, before extubation and one minute after extubation. When the first twitch of TOF (Train of four) (T1) recovered $25 \%$ of the control (T4) or $75 \%$ block remained still as shown by PNS (peripheral nerve stimulator) further increment of either Vecuronium $0.05 \mathrm{mg} / \mathrm{kg}$ or Rocuronium $0.15 \mathrm{mg} / \mathrm{kg}$ was done respectively. Intraoperatively whatever complications occurred were also recorded. After completion of surgery patients were reversed with Neostigmine $0.05 \mathrm{mg} / \mathrm{kg}$ and Atropine $0.02 \mathrm{mg} / \mathrm{kg}$ successively. Statistical analysis was done using programme SPSS (Statistical Package for Social Sciences) 19 version. Chi-square test, Fisher's exact test and Student's t test were used as appropriate and a $p$ value $<0.05$ was taken as statistically significant.

\section{RESULTS}

The demographic parameters (age, weight, gender) were similar between two groups as shown in table 1. Similarly, respiratory parameters were similar in two groups as shown in table 2 and 3 . Table 4 and 5 show haemodynamic parameters. While MAP is similar in two groups throughout surgery, there is a significant reduction in PR in Vecuronium group before and one minute after carboperitonium creation. 
Tabdar S et al.

Table 1: Patients profile in two groups.

\begin{tabular}{lccc}
\hline Patient profile & Group A [Mean \pm SD] & Group B [Mean \pm SD] & P-Value \\
\hline Age (years) & $42.63 \pm 13.720$ & $42.90 \pm 13.005$ & 0.939 \\
Weight (Kilograms) & $53.40 \pm 6.755$ & $52.93 \pm 5.521$ & 0.771 \\
\hline Gender Ratio (male /female) & $6 / 24$ & $5 / 25$ & 1.000 \\
\hline
\end{tabular}

P-value calculated by Student “t”test for age, weight and Fisher's exact test for gender ratio.

Table 2: $\mathrm{SpO}^{2}$ at different events in two study groups.

\begin{tabular}{|lccc|}
\hline Time of recorded variable & Group A [Mean \pm SD] & Group B [Mean \pm SD] & P- Value \\
\hline Baseline & $96.567 \pm 1.6543$ & $96.667 \pm 1.6470$ & 0.815 \\
\hline 1 minute after Muscle Relaxant & $98.600 \pm 1.9226$ & $99.233 \pm 1.0400$ & 0.118 \\
\hline Before Intubation & $98.833 \pm 1.8020$ & $99.433 \pm 1.0063$ & 0.117 \\
\hline 1 minute after Intubation & $99.100 \pm 1.4937$ & $99.467 \pm .9732$ & 0.265 \\
\hline Before Skin Incision & $99.267 \pm 1.5298$ & $99.567 \pm .5040$ & 0.312 \\
\hline 1 minute after Skin Incision & $99.267 \pm 1.2847$ & $99.567 \pm .5040$ & 0.239 \\
\hline Before carboperitoneum & $99.667 \pm .5467$ & $99.533 \pm .5074$ & 0.332 \\
\hline 1 minute after carboperitoneum & $99.567 \pm .5683$ & $99.600 \pm .4983$ & 0.810 \\
\hline Before Extubation & $99.567 \pm .5683$ & $99.567 \pm .5040$ & 1.000 \\
\hline 1 minute after Extubation & $99.567 \pm .5683$ & $99.567 \pm .5040$ & 1.000 \\
\hline
\end{tabular}

P-value calculated by Student " $\mathrm{t}$ " test.

Table 3: ETCO2 at different events in two study groups.

\begin{tabular}{|lccc|}
\hline Time of recorded variable & Group A [Mean \pm SD] & Group B [Mean \pm SD] & P- Value \\
\hline Baseline & $28.400 \pm 3.9444$ & $29.367 \pm 4.9094$ & 0.404 \\
\hline 1minute after Muscle Relaxant & $28.267 \pm 3.9386$ & $30.067 \pm 4.6233$ & 0.110 \\
\hline Before Intubation & $29.167 \pm 4.2676$ & $30.967 \pm 4.0894$ & 0.101 \\
\hline 1minute after Intubation & $30.833 \pm 3.5824$ & $31.667 \pm 4.2291$ & 0.414 \\
\hline Before Skin Incision & $31.700 \pm 3.6022$ & $32.067 \pm 3.8590$ & 0.705 \\
\hline 1minute after Skin Incision & $32.233 \pm 3.4108$ & $31.500 \pm 3.5792$ & 0.420 \\
\hline Before carboperitoneum & $32.033 \pm 4.1062$ & $32.233 \pm 3.3185$ & 0.836 \\
\hline 1 minute after carboperitoneum & $30.367 \pm 3.7827$ & $32.500 \pm 2.9798$ & 0.018 \\
\hline Before extubation & $32.067 \pm 2.6644$ & $32.200 \pm 3.1338$ & 0.860 \\
\hline 1 minute after extubation & $32.467 \pm 2.8616$ & $32.367 \pm 3.0792$ & 0.897 \\
\hline
\end{tabular}

P-value calculated by Student " $t$ " test. 
Table 4: MAP at different events in two study groups.

\begin{tabular}{lccc}
\hline Time of recorded variable & Group A (Mean \pm SD) & Group B (Mean \pm SD) & P- Value \\
\hline Baseline & $94.23 \pm 20.759$ & $85.70 \pm 19.309$ & 0.105 \\
\hline 1 minute after Muscle Relaxant & $83.70 \pm 17.650$ & $80.87 \pm 15.445$ & 0.511 \\
\hline Before Intubation & $82.57 \pm 16.792$ & $82.60 \pm 14.479$ & 0.993 \\
\hline 1 minute after Intubation & $99.50 \pm 19.251$ & $104.03 \pm 16.121$ & 0.327 \\
\hline Before Skin Incision & $93.33 \pm 14.461$ & $93.50 \pm 14.422$ & 0.965 \\
\hline 1 minute after Skin Incision & $99.50 \pm 17.039$ & $99.13 \pm 13.369$ & 0.926 \\
\hline Before carboperitoneum & $95.63 \pm 16.566$ & $91.17 \pm 11.742$ & 0.233 \\
\hline 1 minute after carboperitoneum & $92.80 \pm 24.800$ & $88.43 \pm 13.873$ & 0.403 \\
\hline Before Extubation & $94.03 \pm 14.250$ & $95.57 \pm 13.490$ & 0.670 \\
\hline 1 minute after Extubation & $109.57 \pm 14.567$ & $109.77 \pm 12.605$ & 0.955 \\
\hline
\end{tabular}

P-value calculated by Student "t" test.

Table 5: PR measured at different events in two study groups.

\begin{tabular}{|lccc}
\hline Time of recorded variable & Group A [Mean \pm SD] & Group B [Mean \pm SD] & P -Value \\
\hline Base Line & $81.133 \pm 16.0833$ & $77.667 \pm 15.6212$ & 0.401 \\
\hline 1 minute after Muscle Relaxant & $76.700 \pm 14.4034$ & $81.167 \pm 15.6978$ & 0.256 \\
\hline Before Intubation & $73.867 \pm 14.5026$ & $79.667 \pm 14.8285$ & 0.131 \\
\hline 1 minute after Intubation & $90.90 \pm 14.805$ & $90.77 \pm 14.029$ & 0.972 \\
\hline Before Skin incision & $82.40 \pm 12.260$ & $84.87 \pm 13.480$ & 0.461 \\
\hline 1 minute after Skin incision & $87.77 \pm 12.824$ & $94.03 \pm 14.576$ & 0.082 \\
\hline Before carboperitoneum & $80.033 \pm 13.4202$ & $89.500 \pm 13.6502$ & 0.009 \\
\hline 1 minute after carboperitoneum & $62.800 \pm 11.2569$ & $87.233 \pm 14.3591$ & 0.000 \\
\hline Before Extubation & $85.367 \pm 13.2989$ & $86.233 \pm 13.7055$ & 0.805 \\
\hline minute after Extubation & $99.733 \pm 9.4975$ & $100.000 \pm 13.3106$ & 0.929 \\
\hline
\end{tabular}

P-value calculated by Student " $t$ " test.

Table 6: Complications between two study groups.

\begin{tabular}{lcccc}
\hline Complications & & Group A & Group B & P value \\
Bradycardia & Present & 12 & 0 & $<0.001$ \\
& Absent & 18 & 30 & 0.492 \\
Asystole & Present & 2 & 0 & 30 \\
\hline
\end{tabular}

P-value calculated by Fisher's exact test. 


\section{DISCUSSION}

From our study we found that after comparing Vecuronium or Rocuronium for laparoscopic cholecystectomy as muscle relaxants demographic profile was statistically insignificant with $p>0.05$. Haemodynamic parameters showed significant PR change before and 1 minute after carboperitoneum in Vecuronium group than Rocuronium group where $\mathrm{P}<0.05$, MAP between two groups were statistically insignificant with $p>0.05$. Similarly in respiratory parameters $\mathrm{SpO}_{2}$ between two groups showed statistically insignificant value ( $p>0.05)$ and $\mathrm{ETCO}_{2}$ between two groups again showed statistically insignificant value with $p>0.05$. In Vecuronium group, there was statistically significant number of cases of bradycardia requiring Atropine administration compared to Rocuronium group with $p<0.05$ whereas asystole was statistically insignificant with $p>0.05$.

Vecuronium and Rocuronium are both aminosteroid compounds having good neuromuscular blocking property but showing different cardiovascular effects. Vecuronium shows mild vagotonic activity whereas Rocuronium is mild vagolytic ${ }^{7}$. Booth MG et al compared haemodynamic property of Vecuronium and Rocuronium during Halothane anaesthesia in plastic surgery in 60 patients and found that PR increased in 36\% cases in Rocuronium group than Vecuronium group ${ }^{8}$. Schramm WM et al studied effects of Vecuronium and Rocuronium on ICP (Intracranial pressure), MAP, PR in 20 neurosurgical patients and found that effect of single bolus dose of $0.6 \mathrm{mg} / \mathrm{kg}$ of Rocuronium or $0.1 \mathrm{mg} / \mathrm{kg}$ of Vecuronium was evaluated in patients receiving further continuous anaesthesia with Sufentanyl and Midazolam for 15 minutes where there was no rise of MAP in any groups whereas Rocuronium group showed increased PR in $4 \%$ cases $^{9}$.

\section{REFERENCES}

1. Macmohan AJ, Fischbacher CM, Frame SH, Macleod MC. Impact of Laparoscopic cholecystectomy. Lancet. 2000; 356(11):1632-37.

2. Gutt CN, Oniu T, Mehrabia A. Circulatory and respiratory complications of $\mathrm{CO}_{2}$ insufflation in Laparoscopic cholecystectomy. J Gastroint Surg. 2004;21(2):95-105.

3. Joris JL, Noirot DP, Legrand MJ, Jacquet NJ, Lamy ML. Hemodynamic changes during laparoscopic cholecystectomy. Anaesth Analg. 1993;75:106771.
Robertsen EN and colleagues did a comparative study of Rocuronium and Vecuronium on cardiovascular and intraocular pressure effects on 30 patients after induction with Propofol and Fentanyl. PR, MAP and IOP was measured and found that Rocuronium group showed rise in MAP by $10-15 \%$ and PR by $5-10 \%{ }^{10}$. Shorten GD and colleagues compared haemodynamic effects after administration of Rocuronium $0.6 \mathrm{mg} / \mathrm{kg}$ or Vecuronium $0.1 \mathrm{mg} / \mathrm{kg}$ in 40 elderly patients for plastic surgery patients after equally dividing into two groups. General anaesthesia was given with Propofol, Pethidine and maintained with Oxygen, $\mathrm{N}_{2} \mathrm{O}$ for burn graft. In all of them MAP, PR was measured 1 minute after induction, 1 minute after intubation. The measured values showed that MAP, PR were similar in two groups throughout the operation ${ }^{11}$. Sanjula Virmini et al showed in their study that 60 patients undergoing elective cardiac valve surgery received Rocuronium $0.6 \mathrm{mg} / \mathrm{kg}$ or Vecuronium $0.1 \mathrm{mg} / \mathrm{kg}$ and Pancuronuim $0.1 \mathrm{mg} / \mathrm{kg}$ then PR, MAP were compared. Intra operative results showed that Pancuronium increased PR by $10 \%^{12}$. Harvey et al compared the PR during Gynaecological laparoscopic procedure with Rocuronium or Vecuronium in 116 patients and it seen that patients receiving Rocuronium had very few episodes of bradycardia (1\%) than patients getting Vecuronium where incidence was more than five percent ${ }^{13}$.

\section{CONCLUSION}

Rocuronium is less likely to cause bradycardia as compared to Vecuronium in laparoscopic cholecystectomy while other haemodynamic parameters are similar among them.

4. Rauh R, Hemmorling TM, Rist M, Jacobi KE. Influence of pneumoperitonium and patient positioning on respiratory system compliance. J Clin Anaesth. 2001;13(5):361-65.

5. Pelosi P, Foti G, Cereda M, Vicardi P, Gattinoni L. Effects of carbondioxide insufflation for laparoscopic cholecystectomy on respiratory system. Anaesthesiology. 1996;51:741-7.

6. Miller RD, Rupp SM, Fisher DM. Clinical pharmacology of Vecuronium in laparoscopic cholecystectomy. Anaesthesiology. 1984;61:44453. 
7. Hunter JN. New neuromuscular blocking drugs. N Engl J Med. 1995;332:1691-9.

8. Booth MG, Marsh B, Bryden FM, Robertson EN, Baird WL. A comparison of the pharmacodynamics of Rocuronium and Vecuronium during Halothane anaesthesia. Anaesthesiology. 1992 Oct;47(10):832-4.

9. Schramm WM, Strasser K, Bartunele A, Gilly H, Spiss CK. Effects of Rocuronium and Vecuronium on intracranial pressure, MAP, PR in Neurosurgical patients. BJA. 1996 Nov;77(5):607-11.

10. Robertson EN, Hull AM, Booii LH. A comparison of Rocuronium and Vecuronium on cardiovascular and intraocular pressure effects. Eur Anaesthesiol. 1994;9:116-21.
11. Shorten GD, Lippington J, Comunali MI. Changes in catecholamine concentrations and haemodynamic effects of Rocuronium and Vecuronium on elderly patients. Eur Anaesthesiol. 1998 May;15(3):33541.

12. Sanjula V, Deepak K, Vishnu D. Effects of muscle relaxants on $\mathrm{PR}, \mathrm{BP}$, intubating conditions and onset of neuromuscular block in patients undergoing cardiac valve surgery. Niger Post Grad Med J. 2006 Dec;13(4):313-8.

13. Harvey A, Anderson L, Broome I. A comparison of the effects of Rocuronium and Vecuronium on PR during Gynaecological Laparoscopic surgery. Anaesthesia. 1999 Dec;54(12):1212-16. 